\title{
Lexicography in Asia: its future and challenges
}

\section{Yukio Tono}

Published online: 24 June 2014

(C) Springer Berlin Heidelberg 2014

It is my great pleasure to launch a new journal entitled LEXICOGRAPHY: Journal of ASIALEX. As chief editor, I would like to take this opportunity to thank all of those who have contributed to the organization and administration of ASIALEX for the past 17 years. ASIALEX was established in 1997 at the Dictionaries in Asia conference, which took place at the Language Centre of the Hong Kong University of Science and Technology. Back then, there were already four major regional associations for lexicography: the Dictionary Society of North America (DSNA, founded in 1975), the European Association for Lexicography (EURALEX, founded in 1983), the Australian Association for Lexicography (AUSTRALEX, founded in 1990), and the African Association for Lexicography (AFRILEX, founded in 1995). Following in the steps of these companion associations, ASIALEX was inaugurated on the final day of the Hong Kong conference, in the presence of two prominent scholars in lexicography, Reinhard R. K. Hartmann from the University of Exeter and Gregory James from the Hong Kong University of Science and Technology.

It has since held conferences biennially, in Guangzhou 1999, Seoul 2001, Tokyo 2003, Singapore 2005, Chennai 2007, Bangkok 2009, Kyoto 2011, and Bali 2013. The average number of participants at these conferences was about 200, coming from 20-30 countries in Asia and elsewhere. Emulating the organization of EURALEX, we produced conference proceedings for each conference, which morphed into some important publications such as McArthur and Kernerman (1998), special issues in Studies in Lexicography (2001) from Yonsei University in Seoul, Korea, and Ooi et al. (2009). In the near future, the proceedings' papers will be made available online at the ASIALEX website (http://www.asialex.org).

\footnotetext{
Y. Tono $(\bowtie)$

Tokyo, Japan

e-mail: yukio.tono@gmail.com
} 
It is very timely to launch this Journal because it is the first academic journal that will be devoted to lexicography in Asia. Asia is arguably one of the most dynamic and diverse areas in the world. According to Lewis et al. (2014), there are 7,106 distinct languages in the world, 2,303 of which are living languages spoken in Asia, compared to only 285 spoken in Europe. While we have major languages in terms of the number of native speakers, such as Mandarin Chinese (rank: 1st), Hindi (rank: 4th), Arabic (rank: 5th), Bengali (rank: 7th), Japanese (rank: 9th), and Punjabi (rank: 10th), Lewis et al. report that 692 out of those 2,303 languages are in trouble and 187 languages are dying. Given this diversified yet also unique nature of Asian languages, it is extremely urgent and important to conduct more research to keep a record of and to preserve languages in this part of the world. Promoting the collection of words through field work, the compilation of dictionaries or even small glossaries for indigenous languages, among other things, would be much needed to achieve this goal.

Another good reason for starting the Journal is the significant role of English as an international language and its relation with other languages in Asian contexts. According to the Internet World Stats (http://www.internetworldstats.com/stats7. $\mathrm{htm}$ ), the top 10 languages on the Internet include 4 Asian languages: Chinese (rank: 2nd), Japanese (rank: 4th), Arabic (rank: 7th), and Korean (rank: 10th), while English is unsurprisingly ranked as No. 1. We can see from these figures that the role of Asian languages in this age of the Internet and globalization cannot be emphasized more. The need for more sophisticated natural language processing in these Asian languages will become greater as the Asian market becomes more important in the world economy. Just as in Europe, Asian countries are actively forming various political or economic organizations like ASEAN or TPP and the role of English as the official language is becoming increasingly important. Most countries in Asia, like those in Europe, use native languages as one of their official languages in addition to English, which is why teaching and learning English as an international language are critical issues in each Asian country. ASIALEX has put a strong emphasis on pedagogical lexicography and research on learner's dictionaries and dictionary use (cf. Tono 2001), especially in the context of English as a second/ foreign language. Paying due attention to the role of dictionaries in foreign language learning contexts will provide invaluable insights into more enlightened approaches toward learning English as a lingua franca.

In a similar vein, sound translations between English and the official languages in each country are very important research topics as well as a much needed skill for translators (Munday 2012). Bilingual lexicography deals with the issue of this mapping of meanings between two languages and thus our Journal should provide an excellent platform to compare this mapping across varieties in Asian languages and to study how meanings and forms should be dealt with between the languages (Yong and Peng 2007). Translation studies are also influenced by recent innovations in computer technologies, which make the use of parallel corpora, translation memory, and lexical databases based on those resources integral parts of any professional translator's work (Koehn 2009). Building such resources in conjunction with dictionary making would be a very interesting topic to explore for different Asian languages. 
To meet the demands of processing various Asian languages on computer, the research community is in urgent need of reusable resources such as corpora, POS taggers, treebanks, and lexical resources. Standardizations of exchanging terminologies (e.g., Term Base eXchange) or translation memories (e.g., Translation Memory eXchange) tend to be based on languages in western countries, and they need to be adjusted to the specifications of each language in Asia. With a few exceptions such as Japanese, Arabic, Chinese, and Korean, many Asian languages are still underdeveloped in terms of the construction of ontologies. Data scarcity is even more severe in semantic and verbal resources such as WordNet (Miller 1990), VerbNet (Schuler 2005), FrameNet (Baker, Fillmore and Lowe 1997), or PropBank (Kingsbury and Palmer 2002). A series of workshops on Asian language resources by an organization such as ACL-IJCNLP have been held to explore the possibility of building common lexical resources for Asian languages. One of the realizations so far is that there has not been much exchange of information and the sharing of resources between the NLP researchers and scholars in lexicography as a branch of humanities, commercial dictionary publishers and practical lexicographers. Publishers often have a wealth of ontological data as dictionary contents, but it would be more fruitful to provide a common platform to plan the construction of ontologies by encouraging both sides to work in collaboration. This is even more so for the under-researched languages in Asian regions. It is our hope that lexical resources and their use in NLP will be more readily made available or at least more visible as this Journal addresses the importance of such exchanges to both parties.

Historically speaking, China, Japan and India have a tradition of 1,500-2,000 years in lexicography (cf. Yong and Peng 2008; Tono 2006; Katre 1980). Xu's (121) ShuowenJiezi, for instance, established the radical (semantic primitive) based lexicographical system for dictionaries in the Sinosphere and was adapted in recent works to link dictionaries to an ontology (e.g., Chou and Huang 2010). In this sense, the western tradition of lexicography, however influential it may be in present-day lexicography, should be re-evaluated in the light of Asian lexicography in a historical perspective. The Journal LEXICOGRAPHY will be an important vehicle for conducting such inter-regional and inter-continental research into the history of dictionary making. This will enrich the description of historical lexicography and will be enlightening for those who learn from its history. In the future, our Journal intends to introduce special issues to focus on selected countries or languages in Asia, not only to shed light on various theoretical as well as practical aspects of lexicography facing a particular country or set of languages, but also to bring these issues to the forefront of global research. As chief editor, I do hope that this Journal will facilitate the discussion among lexicographers, dictionary researchers, and publishers across Asia and all over the world. I also hope that this Journal will help to have a deeper understanding of the role of dictionaries or lexical resources in each cultural, political or sociological context and will provide opportunities for more rigorous research collaboration.

The Journal LEXICOGRAPHY is not just about lexicographic studies of Asian languages or meant for the Asian context only. The Journal aims to serve as a leading-edge crossroad and powerhouse assembling all global issues of lexicographic interest, ranging from how to preserve less-resourced and endangered 
languages to how the newest technology could impact the making and usage of dictionaries. It will offer a stage for representing and discussing the increasingly diversified research and development carried out in both academia and industry, drawing from the great many different aspects and qualities of lexicography in Asia, through a pluralistic and interdisciplinary dialogue with the changing worlds of dictionary products and services, linguistics (including computational linguistics and corpus linguistics), native and foreign language learning and teaching, translation (including machine translation, translation memory and artificial intelligence), natural language processing and human language technologies (such as text-to-speech and speech recognition), multilingualism and cross-cultural matters, reference science, and ICT. These seemingly alien fields all interweave with lexicography today.

It is hoped that our inaugural issue offers auspicious omens for future publications. In this issue, we have three papers dealing with specific problems related to lexicography but with potential global implications. Susanna Bae and Hilary Nesi conducted a content analysis of dictionary-related queries on online general-purpose Q \& A sites in the UK and Korea and found interesting differences among the end users' attitudes and concerns in dictionary use. Dora Amalia investigated the design of verb entries in monolingual Indonesian learner's dictionaries by administering needs and skill surveys with prospective users. Danica Salazar examined the lexicon of Southeast Asian varieties of English and its representation in the Oxford English Dictionary. In addition, we have two papers dealing with global issues which will surely strongly impact lexicography in Asia. The article by Kilgarriff et al. introduces the Sketch Engine and describes the stateof-the-art technology in machine-assisted corpus-driven lexicography. The article by Francopoulo and Huang elaborates on the Lexical Markup Framework, an ISO standard that should facilitate the sharing of digital lexica among different sources as well as the setting up of the digital and theoretical infrastructure for all languages to follow in the representation of lexicographical work.

Last but not least, I would like to encourage the readers of this Journal to join our community by contributing papers or by subscribing to LEXICOGRAPHY and become a member of the Asian Association for Lexicography (ASIALEX). Together, we can create even stronger synergy and further enrich the rigorous and promising field of modern dictionary making, use and research in this highly connected age of information and communication technology.

Acknowledgments I would like to thank Gilles-Maurice de Schryver and Chu-Ren Huang for their valuable comments on the earlier draft of this opening statement.

\section{References}

Baker, Collin F., Charles J. Fillmore and John B. Lowe. 1997. The Berkeley FrameNet Project. COLING '98 Proceedings of the 17th International Conference on Computational Linguistics, vol. 1, 86-90. Chou, Ya-Min, and Chu-Ren Huang. 2010. Hantology: conceptual system discovery based on orthographic convention. In Ontology and the Lexicon, eds. C.-R. Huang, N. Calzolari, A. Gangemi, A. Lenci, A. Oltramari, and L. Prevot, 122-143. Cambridge: Cambridge University Press. 
Katre, Sumitra M. 1980. Current trends in Indian lexicography. In Theory and Method in Lexicography. Western and non-western Perspectives, ed. Ladislav Zgusta, 177-189. Columbia, SC: Hornbeam Press.

Kingsbury, Paul, and Martha Palmer. 2002. From Treebank to PropBank. In Proceedings of the 3rd International Conference on Language Resources and Evaluation (LREC-2002).

Koehn, Philipp. 2009. Statistical Machine Translation. Cambridge: Cambridge University Press.

Lewis, M. Paul, Gary F. Simons, and Charles D. Fennig (eds.). 2014. Ethonologue: Languages of the World, 17th edn. Dallas, Texas: SIL International. Online version: http://www.ethonologue.com.

McArthur, Tom, and Ilan Kernerman (eds.). 1998. Lexicography in Asia: Selected papers from the Dictionaries in Asia Conference, Hong Kong University of Science and Technology, 1997 and other papers. Tel Aviv: Password Publishers.

Miller, George A. (ed.). 1990. WordNet: An On-Line Lexical Database. International Journal of Lexicography 3(4): 235-312.

Munday, Jeremy. 2012. Introducing Translation Studies: Theories and Applications. London: Routledge.

Ooi, Vincent, et al. (eds.). 2009. Perspectives in Lexicography: Asia and beyond. Tel Aviv: K Dictionaries.

Schuler, Karin Kipper. 2005. VerbNet: A Borad-Coverage, Comprehensive Verb Lexicon. Unpublished Ph.D. dissertation, University of Pennsylvania.

Studies in Lexicography. vol 11, Nos. 1 and 2. 2001. Seoul: Center for Linguistic Informatics Development, Yonsei University.

Tono, Yukio. 2001. Research on Dictionary Use in the Context of Foreign Language Learning. Lexicographica Series Maior 106. Tübingen: Max Niemeyer Verlag.

Tono, Yukio. 2006. Japanese lexicography. In Encyclopedia of Language and Linguistics, vol. 6, ed. Keith Brown, 105-109. Oxford: Blackwell.

Yong, Heming, and Jing Peng. 2007. Bilingual Lexicography from a Communicative Perspective. Amsterdam: John Benjamins.

Yong, Heming, and Jing Peng. 2008. Chinese Lexicography: A history from 1046 BC to AD 1911. Oxford: Oxford University Press.

Xu, Shen 121. 說文解字 ShuowenJieze (To Explicate the Word and to Parse the Character). 